\title{
Evaluation of Adverse Drug Properties with Cryopreserved Human Hepatocytes and the Integrated Discrete Multiple Organ Co-culture (IdMOC ${ }^{\mathrm{TM}}$ ) System
}

\author{
Albert P. Li \\ In Vitro ADMET Laboratories LLC, 9221 Rumsey Road Suite 8, Columbia, MD 21045
}

(Received March 16, 2015; Revised March 23, 2015; Accepted April 2, 2015)

\begin{abstract}
Human hepatocytes, with complete hepatic metabolizing enzymes, transporters and cofactors, represent the gold standard for in vitro evaluation of drug metabolism, drug-drug interactions, and hepatotoxicity. Successful cryopreservation of human hepatocytes enables this experimental system to be used routinely. The use of human hepatocytes to evaluate two major adverse drug properties: drug-drug interactions and hepatotoxicity, are summarized in this review. The application of human hepatocytes in metabolism-based drug-drug interaction includes metabolite profiling, pathway identification, P450 inhibition, P450 induction, and uptake and efflux transporter inhibition. The application of human hepatocytes in toxicity evaluation includes in vitro hepatotoxicity and metabolism-based drug toxicity determination. A novel system, the Integrated Discrete Multiple Organ Co-culture (IdMOC) which allows the evaluation of nonhepatic toxicity in the presence of hepatic metabolism, is described.
\end{abstract}

Key words: Human hepatocytes, IdMOC, Hepatocyte cryopreservation, Drug metabolism, Drug-drug interactions, Drug toxicity, Drug development

\section{INTRODUCTION}

It is becoming apparent that laboratory animal studies alone are not adequate in the definition of adverse drug effects in the human population. The practice of preclinical safety evaluation is based on the assumption that evaluation of xenobiotic toxicity in multiple animal species should provide data useful for the estimation of human safety. The inadequacy of this assumption is illustrated by findings in

Correspondence to: Albert P. Li, In Vitro ADMET Laboratories LLC, 9221 Rumsey Road Suite 8, Columbia, MD 21045

E-mail: lialbert@invitroadmet.com

Abbreviations: ADMET, Absorption, distribution, metabolism, excretion, toxicity; CHRM, Cryopreserved Hepatocyte Recovery Medium; CYP, Cytochrome P450; DDI, Drug-drug interactions; DILI, Drug induced liver injury; EMA, European Medicines Agency; HCP, Human cell paradigm; HLM, Human liver microsomes; IdMOC, Integrated discrete multiple organ co-culture; PBPK, Physiologically based pharmacokinetic (modeling); US FDA, United States Food and Drug Administration.

This is an Open-Access article distributed under the terms of the Creative Commons Attribution Non-Commercial License (http:// creativecommons.org/licenses/by-nc/3.0) which permits unrestricted non-commercial use, distribution, and reproduction in any medium, provided the original work is properly cited. the pharmaceutical industry, where, in spite of the compulsory vigorous testing in multiple animal species, clinical trial failure rate is estimated to be $85 \%$ or higher (1). Moreover, phase I, II, and III clinical trials are also found not to be adequate as indicated by the numerous post-marketing withdrawals and black-box warnings of marketed drugs (2,7-12).

Species difference in drug metabolism and toxicity. Evidence is being accumulated that the effectiveness of the classical approach of safety evaluation, namely, safety testing in laboratory animals, is hindered by the known speciesdifferences in drug properties, especially ADMET drug properties: absorption, disposition, metabolism, elimination and toxicity (2-4). Species difference is in drug metabolism is a well-established phenomenon. The most important drug metabolizing enzymes belong to the cytochromes P450 isoforms which are localized mainly in the parenchymal cells (hepatocytes) of the liver and are found in other organ such as intestinal epithelium, lung, and kidneys. Of the major isoforms involved in drug metabolism, namely, CYP isoforms $1 \mathrm{~A}, 2 \mathrm{~B}, 2 \mathrm{C}, 2 \mathrm{D}, 2 \mathrm{E}$, and $3 \mathrm{~A}$, the human isoforms are substantially different from those found in rat, dog, and monkey (Table 1).

Drug metabolism is a key determinant in drug toxicity: a toxicant can be rendered more toxic (metabolic activation) 
Table 1. A comparison of human hepatic $P 450$ isoforms to those of the four commonly used laboratory animal species for safety evaluation (mouse, rat, dog and monkey). Extensive species differences have been established, with P450 1A and 2E found to be the only isoforms that are conserved among the multiple animal species. Species difference in P450 isoforms has led to differences in metabolic stability, metabolite profiles, as well as drug toxicity and efficacy. The human isoforms commonly investigated are in bold.

\begin{tabular}{|c|c|c|c|c|c|}
\hline $\begin{array}{l}\text { P450 isoform } \\
\text { subfamily }\end{array}$ & Human & Mouse & Rat & Dog & Monkey \\
\hline $1 \mathrm{~A}$ & $1 \mathrm{~A} 1,1 \mathrm{A2}$ & $1 \mathrm{~A} 1,1 \mathrm{~A} 2$ & $1 \mathrm{~A} 1,1 \mathrm{~A} 2$ & $1 \mathrm{~A} 1,1 \mathrm{~A} 2$ & $1 \mathrm{~A} 1,1 \mathrm{~A} 2$ \\
\hline $2 \mathrm{~A}$ & 2A6, 2A7, 2A13 & $2 \mathrm{~A} 4,2 \mathrm{~A} 5,2 \mathrm{~A} 12,2 \mathrm{~A} 22$ & $2 \mathrm{~A} 1,2 \mathrm{~A} 2,2 \mathrm{~A} 3$ & $2 \mathrm{~A} 13,2 \mathrm{~A} 25$ & $2 \mathrm{~A} 23,2 \mathrm{~A} 24$ \\
\hline $2 \mathrm{~B}$ & 2B6, 2B7 & $2 \mathrm{~B} 9,2 \mathrm{~B} 10$ & $2 \mathrm{~B} 1,2 \mathrm{~B} 2,2 \mathrm{~B} 3$ & 2B11 & 2B17 \\
\hline $2 \mathrm{C}$ & $\begin{array}{l}\mathbf{2 C 8}, 2 \mathrm{C} 9,2 \mathrm{C} 18 \\
\mathbf{2 C 1 9}\end{array}$ & $\begin{array}{l}2 \mathrm{C} 29,2 \mathrm{C} 37,2 \mathrm{C} 38,2 \mathrm{C} 39,2 \mathrm{C} 40 \\
2 \mathrm{C} 44,2 \mathrm{C} 50,2 \mathrm{C} 54,2 \mathrm{C} 55\end{array}$ & $\begin{array}{l}2 \mathrm{C} 6,2 \mathrm{C} 7,2 \mathrm{C} 11,2 \mathrm{C} 12 \\
2 \mathrm{C} 13,2 \mathrm{C} 22,2 \mathrm{C} 23\end{array}$ & $2 \mathrm{C} 21,2 \mathrm{C} 41$ & $2 \mathrm{C} 20,2 \mathrm{C} 43$ \\
\hline $2 \mathrm{D}$ & 2D6, 2D7, 2D8 & $\begin{array}{l}\text { 2D9, 2D10, 2D11, 2D12, 2D13, } \\
\text { 2D22, 2D26, 2D } 34,2 \mathrm{D} 40\end{array}$ & $\begin{array}{l}\text { 2D1, 2D2, 2D3, 2D4, } \\
\text { 2D5, 2D18 }\end{array}$ & 2D15 & $\begin{array}{l}\text { 2D17, 2D19, 2D29, } \\
\text { 2D } 30,2 \mathrm{D} 42\end{array}$ \\
\hline $2 \mathrm{E}$ & 2E1 & $2 \mathrm{E} 1$ & $2 \mathrm{E} 1$ & $2 \mathrm{E} 1$ & $2 \mathrm{E} 1$ \\
\hline $3 \mathrm{~A}$ & $\begin{array}{l}\mathbf{3 A 4}, \mathbf{3 A 5}, 3 \mathrm{~A} 7 \\
3 \mathrm{~A} 43\end{array}$ & $\begin{array}{l}\text { 3A11, 3A13, 3A16, 3A25, 3A41, } \\
3 \mathrm{~A} 44\end{array}$ & $\begin{array}{l}3 \mathrm{~A} 1,3 \mathrm{~A} 2,3 \mathrm{~A} 9,3 \mathrm{~A} 18 \\
3 \mathrm{~A} 62\end{array}$ & $3 \mathrm{~A} 12,3 \mathrm{~A} 26$ & $3 \mathrm{~A} 8$ \\
\hline
\end{tabular}

or less toxic (detoxification) by biotransformation. Species differences in drug metabolizing enzymes such as cytochromes P450 can lead to species differences in xenobiotic toxicity due to differences in rate of metabolic activation and detoxification, as well as differences in metabolite formation. A clear example is the findings of Easterbrook et al. (5) that coumarin to 7-hydroxycoumarin was observed in human but not in rat liver microsomes. The report of Lee et al. (6) is a pioneering study using animal and human hepatocytes in the definition of metabolite formation in drug development. The finding that metabolites formed by rat hepatocytes were different from those formed by human hepatocytes suggest that, for the drug candidate evaluated, the rat was not an appropriate experimental for human. This species differences in metabolite formation is now a frequently observed phenomenon in drug development.

Human cell paradigm (HCP) for the prediction of human drug properties. I propose here the HCP for human safety evaluation. With the HCP, human-specific adverse drug properties are obtained using physiologically relevant human cell based in vitro experimental systems, followed by prediction of human in vivo effects using two methods: 1. Direct extrapolation of in vitro results to human in vivo using known human in vivo parameters (e.g. physiologically based pharmacokinetics data; genetic polymorphism; environment factors). This approach has been applied successful in the estimation of hepatic metabolic clearance and drug-drug interactions. 2. Develop in vitro animal results using similar cell systems from multiple species for the selection of the most relevant animal species for in vivo evaluation and extrapolation of results to humans in vivo. This approach is recommended for safety studies such as hepatotoxicity. The key emphasis is that human-specific drug properties obtained using in vitro human-based experimental systems are critical to the evaluation of human in vivo drug properties (Fig. 1).

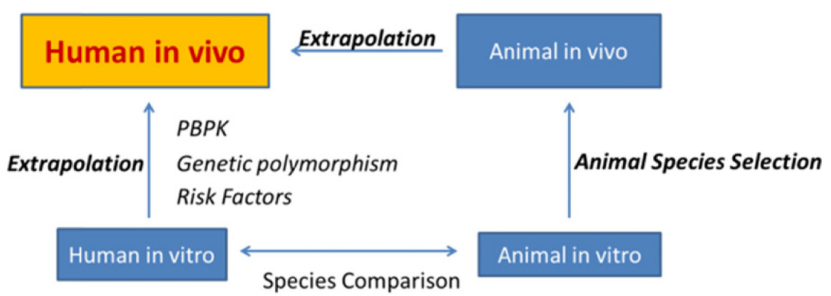

Fig. 1. Human cell paradigm (HCP) for the prediction of human drug properties. With the HCP, emphasis is placed on human-specific drug properties obtained with physiologically relevant human-based in vitro experimental systems. In vitro results are then extrapolated to in vivo based on known human in vivo parameters or via the selection of the most appropriate animal species using similar in vitro systems, followed by in vivo evaluation in the chosen animal species.

Human hepatocyte as a key experimental system for the assessment of adverse human drug properties. As the body's major organ for drug metabolism, the liver plays an important role in drug properties. Biotransformation of drugs determines the duration (metabolic stability) of the drug in the systemic circulation. Hepatic metabolites are known to exhibit toxicological and pharmacological properties which may be different from the parent drugs. Further, drug-drug interactions and liver toxicity are adverse drug properties that have been found to lead to clinical trial failures or withdrawal of marketed drugs (7-12). Human hepatocytes, the parenchymal cells in the human liver, are the key hepatic cells for drug metabolism and when damaged, would lead to hepatic injuries. Severe drug-induced damages to hepatocytes has caused liver failure, leading to a need for liver transplantation and have resulted in deaths $(2,10)$.

Hepatocytes represent the most important cell type for the evaluation of drug metabolism and are generally considered the "gold standard" for in vitro drug metabolism and 
hepatotoxicity studies. The advantages of hepatocytes over other in vitro hepatic experimental systems such as liver homogenate, post-mitochondrial supernatants, and microsomes, are attributed to the various intact cell properties including the intact cell membrane with active transporter functions, complete and uninterrupted metabolic pathways, and metabolic enzymes and cofactors at physiologically relevant concentrations $(3,13)$.

Isolation, cryopreservation, and culturing of human hepatocytes. Human hepatocytes can be isolated from human liver biopsies or whole livers which have been donated, but not used, for transplantation. The application of human hepatocytes in research was limited by the general unavailability of human livers for research and the lack of hepatocyte isolation expertise in most laboratories. Success in human hepatocyte cryopreservation in the recent decade allows the cells to be used routinely for experimentation (14-16). Hepatocytes are generally used as suspension cultures for short-term (hours) studies, and as monolayer cultures for longer-term (days) studies. The loss of polarity of cultured hepatocytes is overcome by culturing the cells in a collagen Matrigel sandwich (culturing of hepatocytes on a collagen-coated surface, followed a thin overlay of Matrigel). The properties (viability; yield; P450 activities) of cryopreserved human hepatocytes are shown in Table 2.

We dedicated extensive effort in our laboratory towards the optimization of hepatocyte isolation, cryopreservation, and post-cryopreservation recovery. A major advancement is the development of a specialized medium (Cryopreserved Hepatocyte Recovery Medium $\left(\mathrm{CHRM}^{\mathrm{TM}}\right)$ which greatly enhances the post-thaw viability of hepatocytes. Upon recovery in CHRM, the viability (based on dye exclusion) is routinely $>85 \%$ (Table 1 ). Furthermore, approximately
$50 \%$ of the human hepatocyte isolations result in cryopreserved hepatocytes that form monolayer cultures with $>80 \%$ confluency (plateable cryopreserved human hepatocytes). We now have extended human hepatocyte cryopreservation to the preparation of cryopreserved human hepatocytes pooled from multiple donors: cryopreserved hepatocytes from individual donors are thawed, cells from multiple donors are pooled, and the cells re-cryopreserved. While individual donors can be used to illustrate individual differences, the pooled cryopreserved hepatocytes can be used for the investigation of drug properties towards a "normalized" human population.

We are also successful in the cryopreservation of nonhuman animal hepatocytes. Cryopreserved hepatocytes from multiple animal species and human can be used in the same experiment for the selection of the animal species most resembling human in the drug property of interest.

The morphology of cultured cryopreserved human and animal hepatocytes is shown in Fig. 2. Morphology of pooled cryopreserved human hepatocytes is shown in Fig. 3.

\section{Application of human hepatocytes in the evaluation} of human drug properties. Cryopreserved human hepatocytes are now a universally accepted experimental system for the evaluation of human drug properties. This system is used routinely in pharmaceutical industry for drug discovery and development. Regulatory agencies such as European Medicines Agency (EMA) and United States Food and Drug Administration (US FDA) explicitly recommend drug metabolism and drug-drug interaction evaluations using cryopreserved human hepatocytes. As of this writing, cryopreserved human hepatocytes are available commercially and are routinely used for studies involving drug metabolism, drug-drug interactions such as drug metabolizing

Table 2. Donor demographics, post-thawed viability, yield, and P450 isoform-selective substrate metabolism activities of plateable cryopreserved human hepatocytes. The consistently high viability (majority of lots are $>90 \%$ ) is a function of the optimized procedures used in the isolation, cryopreservation, and thawing of cryopreserved cells. Universal Cryopreservation Recovery Medium (UCRM) is especially important in thawing and recovery of cryopreserved hepatocytes. Viability was determined by trypan blue exclusion. The metabolic pathways evaluated were: phenacetin 1-hydroxylation (CYP1A2), bupropion hydroxylation (CYP2B6), paclitaxel 6 $\alpha$-hydroxylation (CYP2C8), diclofenac hydroxylation (CYP2C9), dextromethorphan hydroxylation (CYP2D6), chlorzoxazone 6hydroxylation (CYP2E1), and testosterone 6 $\beta$-hydroxylation (CYP3A4), with activity expressed as pmol/million hepatocytes/min (F: female; M: male; C: Caucasian; H: Hispanic; BMl: body mass index).

\begin{tabular}{|c|c|c|c|c|c|c|c|c|c|c|c|c|c|}
\hline $\begin{array}{c}\text { Lot } \\
\text { number }\end{array}$ & Ethnicity & Gender & $\begin{array}{c}\text { Age } \\
\text { (years) }\end{array}$ & BMI & $\begin{array}{c}\text { Viability } \\
(\%)\end{array}$ & Yield & CYP1A2 & CYP2B6 & CYP2C8 & CYP2C9 & CYP2D6 & CYP2E1 & CYP3A4 \\
\hline НH1007 & $\mathrm{C}$ & $\mathrm{F}$ & 26 & 26.9 & 94.0 & 5.4 & 140.0 & 143.5 & 3.8 & 80.5 & 177.5 & 240.8 & 398.3 \\
\hline НH1020 & $\mathrm{C}$ & $\mathrm{F}$ & 21 & 23.2 & 89.1 & 4.9 & 237.5 & 507.5 & 2.1 & 74.3 & 112.1 & 229.5 & 843.2 \\
\hline HН1025 & $\mathrm{C}$ & $\mathrm{F}$ & 59 & 32.8 & 90.1 & 5.6 & 28.0 & 66.6 & 0.7 & 58.8 & 11.4 & 120.4 & 126.4 \\
\hline HН1031 & $\mathrm{H}$ & M & 42 & 43.6 & 93.0 & 5.5 & 12.7 & 81.0 & 2.3 & 59.8 & 18.0 & 38.0 & 179.2 \\
\hline HН1033 & $\mathrm{C}$ & $\mathrm{F}$ & 40 & 44.9 & 94.0 & 6.2 & 31.1 & 18.3 & 1.3 & 66.0 & 19.4 & 35.9 & 73.9 \\
\hline НH1036 & $\mathrm{C}$ & M & 55 & 26.0 & 94.0 & 7.0 & 37.5 & 39.0 & 1.4 & 74.6 & 6.9 & 49.2 & 512.8 \\
\hline HН1045 & $\mathrm{H}$ & M & 9 & 19.5 & 90.0 & 9.0 & 51.9 & 19.5 & 1.4 & 90.3 & 35.5 & 38.9 & 311.4 \\
\hline HH1051 & $\mathrm{C}$ & M & 23 & 25.3 & 97.0 & 5.5 & 59.5 & 71.8 & 0.2 & 55.0 & 2.5 & 34.2 & 17.9 \\
\hline HH1052 & $\mathrm{C}$ & $\mathrm{M}$ & 44 & 24.1 & 92.0 & 7.6 & 399.0 & 68.7 & 0.5 & 249.9 & 27.3 & 35.8 & 46.3 \\
\hline
\end{tabular}




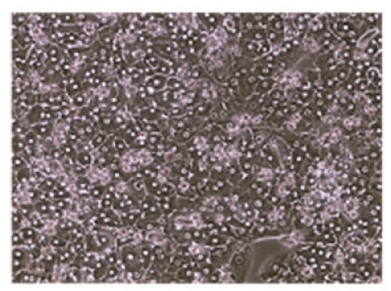

Human

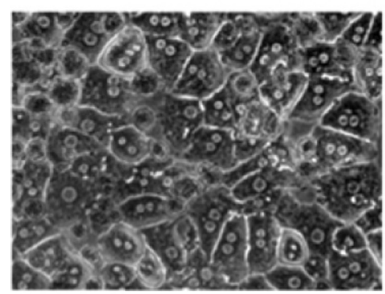

CD-1 Mouse

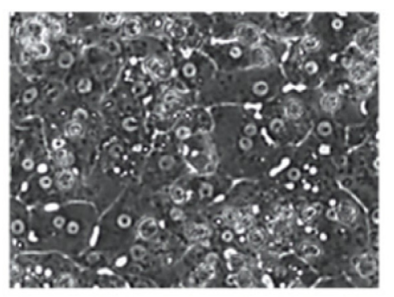

Cynomolgus Monkey

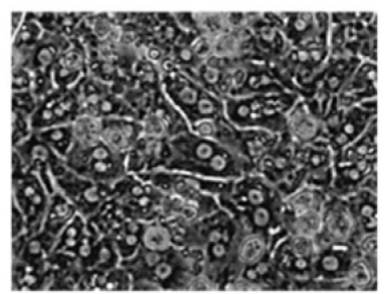

SD Rat

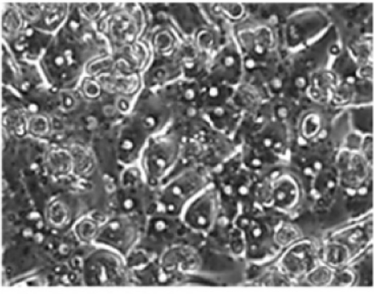

Beagle Dog

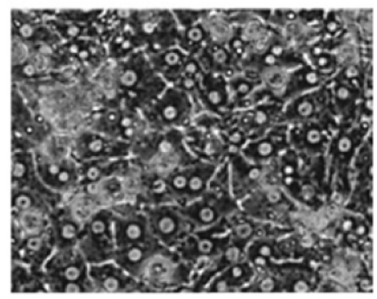

Wistar Rat

Fig. 2. Morphology of cultured cryopreserved human and animal hepatocytes. The cryopreserved hepatocytes formed highly confluent (near 100\%) cultures and exhibited the cobble-stone shape typical of freshly isolated hepatocytes. The successful cryopreservation allows simultaneous experimentation of hepatocytes from human and multiple animal species for the selection of the most appropriate animal species for in vivo assessment of human drug properties as described for human cell paradigm (HCP). [Phase-contrast microphotograph (200× magnification)].

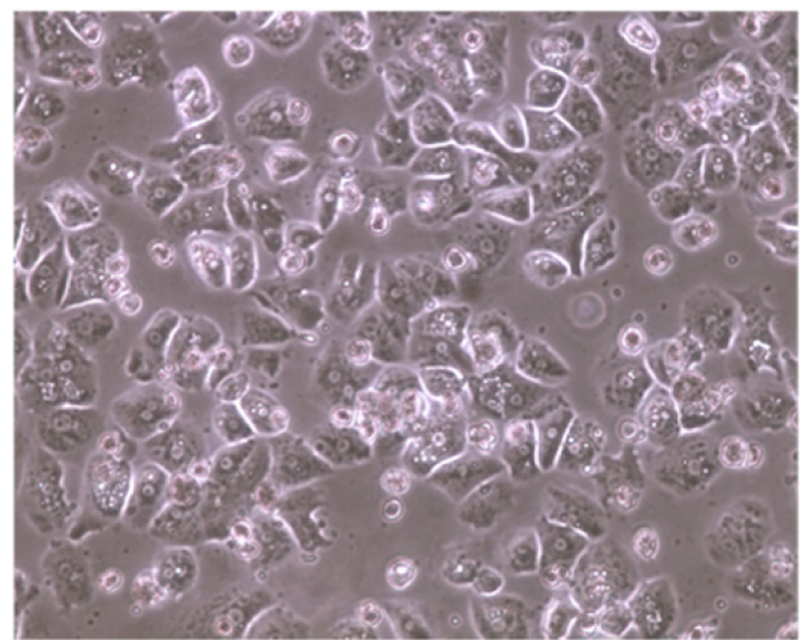

Fig. 3. Morphology of pooled cryopreserved human hepatocytes. Hepatocytes from 5 lots of plateable cryopreserved hepatocytes were thawed, pooled, and cryopreserved. The ability of hepatocytes to be cryopreserved two times to retain viability and plateability demonstrates the effectiveness of cryopreservation technology. [Phase-contrast microphotograph (200× magnification)].

enzyme inhibition and induction, and drug toxicity (3). The most recent application is the assessment of transportermediated hepatic uptake (17-20) and efflux (21-23), timedependent enzyme inhibition (24-28), as well as the evaluation of metabolism-dependent drug toxicity $(29,30)$. The scientific concepts of these adverse drug effects and the human hepatocyte assays developed for their assessment are reviewed here.

Drug-drug interactions (DDI): When a drug affects the efficacy and toxicity of a co-administered drug, the results may have grave consequences. DDI may be due to pharmacological mechanisms, leading to potentiation of efficacy (e.g. interacting with different pathway yielding complementary pharmacological effects), or reduction of efficacy of a co-administered drug (e.g. antagonistic competition for the same receptors). Pharmacological interactions may lead to serious consequences due to exaggerated pharmacological effects as exemplified by the severe blood pressure drop upon co-administration of sidenafil and nitroglycerine (31). Pharmacological DDI in general are readily managed due to the well-defined pharmacological properties of the marketed drugs.

Serious consequences are usually attributed to pharmacokinetic DDI where one drug significantly alters the metabolic fate of a co-administered drug. The evaluation of DDI potential in general is focused on the major human CYP isoforms, with the most important isoform being CYP3A4, which is known to metabolize $>50 \%$ of existing drugs (32). The mechanism of metabolism-based DDI can be inhibitory or inductive.

I. Inhibitory DDI: Inhibition of drug metabolizing enzyme activity by one drug (the perpetrator drug) can lead to diminished metabolism of a co-administered drug (the victim drug) that is mainly cleared by the inhibited pathway. This leads to an increase in systemic burden of the victim drug, which may result in toxic events. A clear example of this type of inhibitory drug-drug interactions is the terfenadine-induced cardiac arrthymia (Torsade des Pointes) upon 
co-administration of terfenadine with drugs that are inhibitors of CYP3A4 (33-35). Upon ingestion, terfenadine is rapidly and effectively metabolized by hepatic CYP3A4. Co-administration with CYP3A4 inhibitors such as ketoconazole, itraconazole and erythromycin would lead to elevation of plasma levels of terfenadine to cardiotoxic levels, resulting in severe, sometimes fatal cardiotoxicity. Terfenadine was subsequently removed from the market and replaced by the pharmacological active but nontoxic metabolite, fexofenadine (36).

II. Inductive DDI: Another type of drug-drug interaction is inductive DDI, where the perpetrator drug would accelerate the metabolic clearance of a co-administered victim drug via the induction of a drug metabolism pathway. A major consequence of inductive DDI is the lowered pharmacological activity (loss of efficacy) of the affected victim drug which can have serious consequences. An example of inductive drug-drug interactions is the induction of the metabolism of drugs that are CYP3A4 substrates by the potent enzyme inducer rifampin (37-40). An example of the serious consequence of inductive DDI is the lowered cyclosporine plasma levels in a patient co-administered with rifampin, leading to rejection of a transplanted kidney (41).

III. Transporter-based DDI: It is now well-recognized that many drug transporters can play key roles in drug disposition. Many drugs are not freely permeable to cellular plasma membrane, but would enter or exit a cell as substrates of uptake or efflux transporters, respectively. In the intestinal epithelium, the efflux transporter P-glycoprotein (Pgp) can transport an absorbed drug back into the lumen. In the liver, uptake transporters [e.g. organic anion transporter 1 (OAT1) and efflux transporters (e.g. multiple drug resistance protein (MDR1)] of the hepatocyte plasma membrane are key determinants of intracellular concentrations, and thereby impact metabolism and toxicity of substrate drugs. Drugs that are transporter inhibitors can cause DDI with drugs that are substrates of the inhibited transporters.

It is now known that clinically significant DDI can occur due to interactions with drug transporters, leading to alterations of cellular uptake and efflux. Clinically significant transporter-based DDI have been found in small intestine, liver and kidney (42-45). Evaluation of transporter-based DDI potential of drug candidates is now recommended by regulatory agencies including US FDA and EMA for marketing approval (46-48).

IV. Human hepatocyte-based assays for metabolism and transporter-based DDI: In vitro evaluation of metabolismbased and transporter-based DDI are now routinely used in drug development and are required for regulatory approval (48-51). Human hepatocytes are used routinely for this endeavor.

1. Metabolite profiling and pathway identification: In general, pathway identification assessment of the major drug-metabolizing enzyme pathways involved in the metab- olism of the drug in question is the first step of DDI assessment. One of the most useful applications of hepatocytes in DDI evaluation is the generation of a complete metabolite profile, allowing the assessment of the major metabolic pathways $(52,53)$. The observation of oxidative metabolites such as hydroxylated metabolites and the respective conjugates would indicate that phase 1 metabolism is involved, and DDI may occur with drugs that are inhibitors or inducers of the phase 1 pathways such as P450 isoforms. Direct conjugation metabolites would suggest the involvement of phase 2 pathways, and thereby DDI may occur with inhibitors of phase 2 conjugating enzymes. Upon the completion of metabolite profiling, enzyme-selective inhibitors and inducers are used to further identify the specific drug metabolizing enzymes (54). It is to be noted that metabolite profiling using hepatocytes from multiple species is a wellaccepted approach to select the most appropriate nonhuman animal species for in vivo metabolism studies.

2. P450 inhibition studies: As for metabolic stability, HLM are used routinely for inhibitory DDI evaluation (55). In general, P450 inhibition studies - evaluation of the inhibitory potential of a drug candidate on the major $\mathrm{P} 450$ isoforms: CYPs 1A2, 2A6, 2B6, 2C8, 2C9, 2C19, 2D6, 2E1 and $3 \mathrm{~A} 4$, are required for regulatory approval. It is now believed that the use of hepatocytes will provide additional insight on inhibitory potential of a drug based on plasma levels (3). The use of intact hepatocytes allow drug partitioning, with the most important being bioaccumulation due to hepatocytes via uptake transporters. The use of hepatocytes may also generate data on the inhibitory potential of metabolites. For instance, gemfibrozil is a potent inhibitor of CYP2C8 in hepatocytes but not in HLM due to the formation of the potent metabolite inhibitor, gemfibrozil glucuronide, in hepatocytes (56). Procedures for the evaluation of time-dependent P450 inhibition have been established in human hepatocytes $(24-26,28)$. A recent advance is the use of the luminescent substrate luciferin IPA in human hepatocytes to increase throughput for the evaluation of the inhibition of CYP3A4, the P450 isoform that is key to many cases of clinically significant DDI $(26,57,58)$.

3. P450 induction studies: Primary cultured human hepatocytes represent the gold standard for P450 induction studies (14,59). Induction of CYP1A2, CYP2B6 and CYP3A4, each representing the nuclear receptors aryl hydrocarbon receptor (AhR), constitutive androstane receptor (CAR), and pregnane $\mathrm{X}$ receptor (PXR), respectively, are required by regulatory agencies internationally. Experimental protocols have been developed to improve the efficiency of P450 induction studies via the use of P450 substrate cocktails (60-62) and the use of multi-well plates, including 48- and 96-well formats $(63,64)$. The use of luciferin-IPA as a substrate greatly improves the efficiency of CYP3A induction studies $(57,58)$. While enzyme activity has been regarded as the most relevant endpoint for $\mathrm{P} 450$ 
induction studies, data have been generated suggesting that quantification of gene expression may provide more relevant results, especially for inducers that also inhibit enzyme activities $(65,66)$.

4. Efflux transporter inhibition: Efflux transporters play important roles in drug disposition, with the key organs being the intestine for the uptake of orally-administered drugs, the liver for hepatic uptake of absorbed drugs, and the brain where efflux transporters play a key role in the blood-brain barrier. Experimental approaches have been developed for the evaluation drug-modulation of efflux transporters. While induction has been observed with efflux transporters, clinically-significant DDI are observed mainly with inhibitory effects.

a. Pgp (MDR-1) inhibition studies: As discussed earlier, Pgp inhibition by a drug may increase intestinal absorption via decreased efflux of a co-administered drug that is a substrate of the inhibited transporter. Pgp inhibition is generally studied in vitro in cellular models of the intestinal epithelium such as a human colon carcinoma Caco-2 cells, which, when cultured as polarized monolayer culture, are known to express Pgp, and in the Pgp-transfected MadinDarby canine kidney (MDCK) cells $(67,68)$.

b. Hepatic efflux transporter studies: Inhibition of efflux transporters in hepatocytes may lead to accumulation of a co-administered drug which is a substrate of the inhibited transporter. Furthermore, as hepatic efflux transporters are involved in bile salt excretion, an efflux inhibitor may lead to bioaccumulation of bile salts, leading to hepatotoxicity. Collagen-matrigel sandwiched human hepatocyte cultures are known to express efflux transporters and are used for inhibition studies $(22,23,69-75)$.

5. Uptake transporter inhibition: It is now well-accepted that cryopreserved human hepatocytes can be used routinely to evaluate transporter-mediated drug uptake $(20,70)$. In vitro quantification of inhibitory DDI mediated by uptake transporters can be coupled with Physiologically based pharmacokinetic (PBPK) modeling to assess clinical effects (76-81).

Hepatotoxicity. Drug-induced hepatotoxicity is a major challenge in drug development. In spite of the extensive preclinical safety testing in laboratory animals, severe hepatotoxicity remains a major reason for clinical trial failure and withdrawal of marketed drugs (82-84). Extensive efforts are being invested to develop both clinical and preclinical approaches to minimize drug induced liver injury (DILI) $(82,85-88)$. Species difference in sensitivity to drug toxicity and rare incidence due to the requirement of co-occurrence of multiple events are two possible reasons for the difficulty in the preclinical and clinical safety assessment in drug development $(2,89)$.

Hepatic metabolism (90-93) and bile salt efflux transporter inhibition (94-96) are now believed to play critical roles in DILI. Hepatic xenobiotic metabolism may lead to the formation of reactive metabolites, leading to inactivation of critical biochemical pathways and ultimately, toxicity. The hapten hypothesis states that DILI may occur as a result of cytotoxic immune interaction with neoantigens resulting from covalent binding of reactive metabolites to cellular proteins.

Primary cultured human hepatocytes, with near normal xenobiotic metabolic capacity and efflux transporter activity, represent one of the most relevant in vitro models for early evaluation of DILI potential of drug candidates. In vitro cytotoxicity assays with primary human and animal hepatocytes are now used routinely for in vitro screening of hepatotoxic potential during drug development.

1. Cytotoxicity assays: Cytotoxicity can be readily quantified in cryopreserved human hepatocytes cultured as monolayer cultures on collagen-coated vessels, with throughput enhanced via the use of multiwall plates including 96-, 384-, and 1536-well plates (97-103). Via the use of various endpoints, one can assess the mechanism of cytotoxic effects. MTT or MTS metabolism and cellular ATP content are used to quantify cytotoxicity due to mitochondrial impairment. Release of cytoplasmic enzymes such as lactate dehydrogenase, AST, and ALT indicate plasma membrane damage. Caspase activation measures apoptosis. A decrease in reduced glutathione concentration suggests the formation of reactive metabolites. Finally, quantification of reactive oxygen species (ROS) indicates oxidative stress. The use of the endpoints in combination (high-content multi-parameter cytotoxicity assay) has been reported to increase the accuracy of toxicity prediction $(87,104,105)$. Cytotoxicity screening assays with hepatocytes from multiple animal species can aid the selection of nonhuman animal species for in vivo safety studies $(99,106)$.

2. Toxicogenomics: The use of microarrays allows the evaluation of the effects of toxicants on a multitude of genes. Human hepatocytes have been used in conjunction with toxicogenomics for the identification of biomarkers of toxicity with some success $(107,108)$. Data mining from both hepatocytes in vitro and animals in vivo appear to be promising in the identification of gene signatures for hepatotoxicity (109).

3. Metabolism-based cytotoxicity assay: Biotransformation is a key determinant of drug toxicity. Metabolic activation (formation of toxic metabolite from a relatively nontoxic parent) is a well-established phenomenon $(110,111)$. Examples of metabolically-activated toxicants include the environmental toxicant benzo(a)pyrene (112), the food contaminant aflatoxin B1 $(29,113)$, the hepatotoxic drug acetaminophen $(114,115)$, and the anticancer drug cyclophosphamide $(116,117)$. Conversely, metabolic detoxification can lead to lower toxicity $(118,119)$. Definition of the roles of metabolism in drug toxicity may lead to a better understanding of inter-individual differences, which is a major challenge in safety assessment. In our laboratory, assays have been 
developed to define the role of metabolism in drug toxicity using metabolic inhibitors as well as a comparative cytotoxicity assay using hepatocytes and a metabolically-incompetent cell line, the mouse 3 T3 cells (29). Using a novel co-culture system, the Integrated Discrete Multiple Organ Co-culture $\left(\mathrm{IdMOC}^{\mathrm{TM}}\right)$, an in vitro assay has been developed to evaluate the role of hepatic metabolism on the cytotoxicity of a drug to hepatocytes and to nonhepatic cells $(14,120-124)$.

\section{Identification of drugs with potential to cause liver} failure. One major challenge in the clinical management of drug-induced liver injuries is that the current biomarkers (such as serum alanine aminotransferase (ALT) and aspartate aminotransferase (AST)) do not always accurately predict the final outcome. Primary cultured human hepatocytes represent an experimental system that may be useful in the identification of biomarkers that can accurately define the onset of serious liver injuries. For instance, in a collaborative study with U. S. FDA National Center for Toxicological Research, our laboratory identified oxidative stress/ATP ratio as an accurate biomarker for drugs that are associated with severe liver injuries (unpublished data), suggesting that oxidative stress-associated products in body fluids may be useful in the assessment of the onset of severe liver injuries. Toxic mechanisms discovered in hepatocytes may aid the detection of occurrence of such events in vivo. Transient elevation of serum bile salt for instance, has been correlated with hepatotoxicity due to inhibition of bile salt efflux protein (BSEP) (125). Cultured hepatocytes can also be used to substantiate the mechanistic relevance of promising biomarkers found in vivo (86) via correlation of the signal of the biomarkers and hepatocyte cytotoxicity in vitro. Toxicogenomics (108), proteomics (126) and metabolic (127) studies with hepatocytes may reveal novel toxic pathways that may lead to discovery of unique biomarkers which can be readily quantified in body fluids as early indicators of liver injuries.

Nonhepatic toxicity and the Integrated Discrete Multiple Organ Co-culture (IdMOC ${ }^{T M}$ ) experimental system. As described above, hepatocytes represent an effective in vitro experimental model for the evaluation of hepatotoxicity. Similar approaches can be used for the evaluation of toxicity with nonhepatic organs such as heart, lung, kidney, intestines, vascular systems, etc., using key cell types from each of the organs to be evaluated. The currently available primary cell systems and the respective organ-specific toxicity that can be evaluated include the following:

- Hepatocytes (hepatotoxicity)

- Renal proximal tubule epithelial cells (nephrotoxicity)

- Vascular endothelial cells (vascular toxicity)

- Neuronal cells, glial cells and astrocytes (neurotoxicity)

- Cardiomyocytes (cardiotoxicity)

- Bone marrow cells (bone marrow toxicity)
The absence of hepatic metabolism is a well-recognized major drawback of the use of nonhepatic cells to evaluate nonhepatic organ toxicity. As described earlier, hepatic metabolism is a key determinant of drug toxicity. A drug can be rendered more toxic (metabolic activation) or less toxic (detoxification) due to hepatic metabolism. The IdMOC experimental system has been developed to allow the incorporation of hepatic metabolism in the evaluation on nonhepatic toxicity.

The IdMOC system involves the "wells-in-a-well" concept. The typical IdMOC plate consists of a chamber within which are several wells (Figs. 4 and 5). Cells of different origins (e.g. from different organs) are initially cultured, each in its specific medium, in the wells. When the cells are established, the wells are flooded with an overlying medium, thereby connecting all the wells within each chamber. The multiple cell types now can interact via the overlying medium, akin to the multiple organs in a human body interacting via the systemic circulation. The advantage of the IdMOC system is that one can evaluate differential cytotoxicity of a toxicant towards multiple cell types under nearidentical experimental conditions, with interaction among multiple cell types allowed via the overlying medium. As the multiple cell types are physically separated, the effect of a toxicant on each particular cell type can be evaluated individually after experimentation. An IdMOC culture has

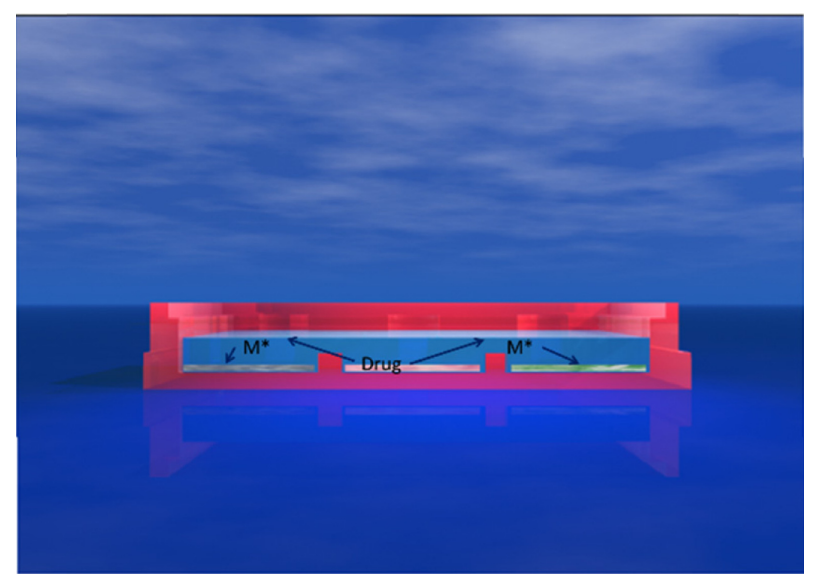

Fig. 4. Schematic representation of the IdMOC experimental system. IdMOC consists of multiple shallow wells within a larger containing well (chamber). Cells are plated firstly into the shallow wells (one cell type per well) to allow attachment and growth. Upon establishment of the cultures, the shallow wells are flooded with a co-culture medium, allowing cells from the difference inner wells to communicate via soluble factors. An important application of IdMOC is to evaluate the toxicity of hepatic metabolites on nonhepatic cells as illustrated here with a drug metabolized by hepatocytes from the center well to form metabolites $(M)$ that are released by the hepatocytes into the medium and ultimately interacting with nonhepatic cells cultured in a different well in the chamber. 


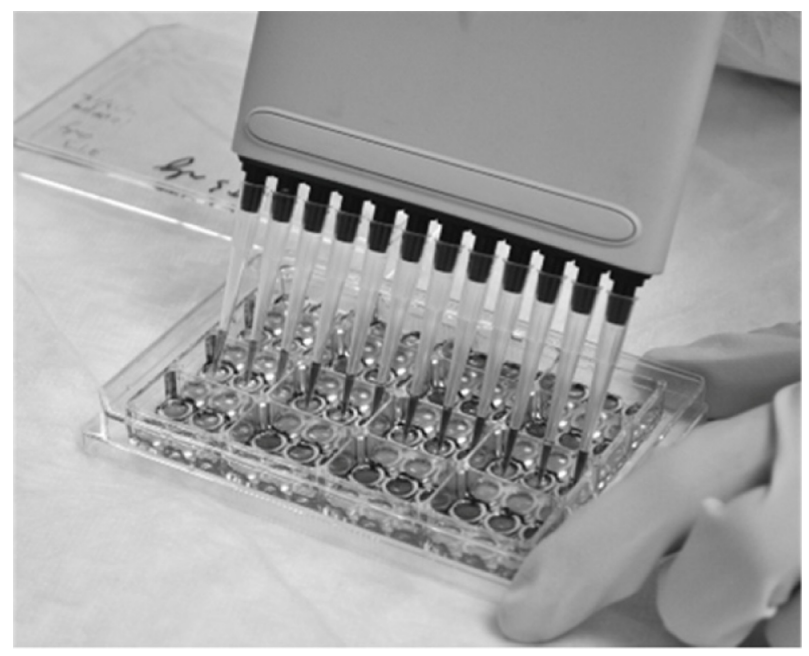

Fig. 5. Photograph of an IdMOC multi-well plate with sixteen chambers and six inner wells per chamber (IdMOC-96). The plate has the same footprint of a regular 96 -well plate and is compatible with multi-channel pipets.

advantages over co-culturing of multiple cell types as mixed cultures in the same cell culture vessel as the cell types evaluated may not have physical contacts in vivo, and that it would be very challenging, if not physically impossible, to separate the different cell types after experimentation to evaluate the effects of the toxicants being studied $(121,123,124)$.

Applications of IdMOC include the following:

1. Differential cytotoxicity: Evaluation of the toxicity of a substance on different cell types (e.g. cells from different organs) under virtually identical experimental conditions with multiple cell-type interactions.

2. Differential distribution: Evaluation of the differential accumulation/distribution of a substance among multiple cell types. This application is especially useful for the development of cytotoxic anticancer agent with selective affinity towards cancer cells.

3. Incorporation of hepatic metabolism: Via the co-culturing hepatocytes with nonhepatic cells in the IdMOC, one can evaluate the role of hepatic metabolism on the toxicity of a toxicant towards the nonhepatic cells. We have reported the use of IdMOC co-cultures of metabolically hepatocytes and mouse 3T3 cells to demonstrate this major application of IdMOC, namely, the incorporation of hepatic metabolism in the evaluation of cyclophosphamide, a toxicant that is metabolically activated (30) (Fig. 6). Recently, we also have used IdMOC to demonstrate detoxification using aminophenol, a toxicant that is known to be metabolically detoxified.

4. Whole body IdMOC: A new configuration of IdMOC has been developed in our laboratory. We now have IdMOC with 48 and 96 inner wells within each outer well, thereby allowing a larger variety of cells to be co-cultured. An example of an IdMOC-man by co-culturing cells from mul-

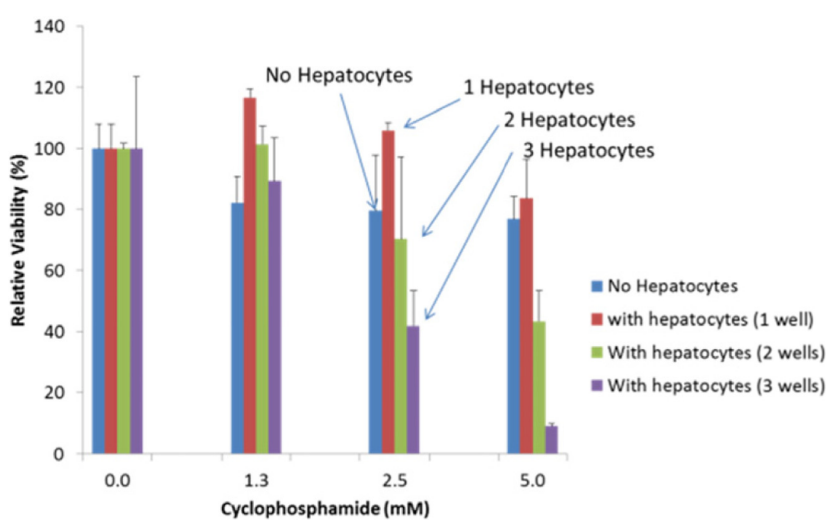

Fig. 6. Cyclophosphamide cytotoxicity in IdMOC with human hepatocytes and $3 \mathrm{~T} 3$ cells. Each IdMOC chamber is seeded with 3 wells of 3 T 3 cells co-cultured with $0,1,2$, and 3 wells of hepatocytes. The chambers are flooded with medium containing $0,1.25,2.5$ and $5 \mathrm{mM}$ of cyclophosphamide. Dose-dependent cytotoxicity to 3T3 cells was observed only in the presence of 2 and 3 wells of hepatocytes, demonstrating the release of cyclophosphamide metabolites from hepatocytes to cause cytotoxicity in the metabolically-incompetent 3T3 cells. The system can be adopted to evaluate cytotoxicity of hepatic metabolites to any other nonhepatic cell types by simply replacing the 3T3 cells with the cell type of interest (e.g. cardiomyocytes for in vitro cardiotoxicity studies).

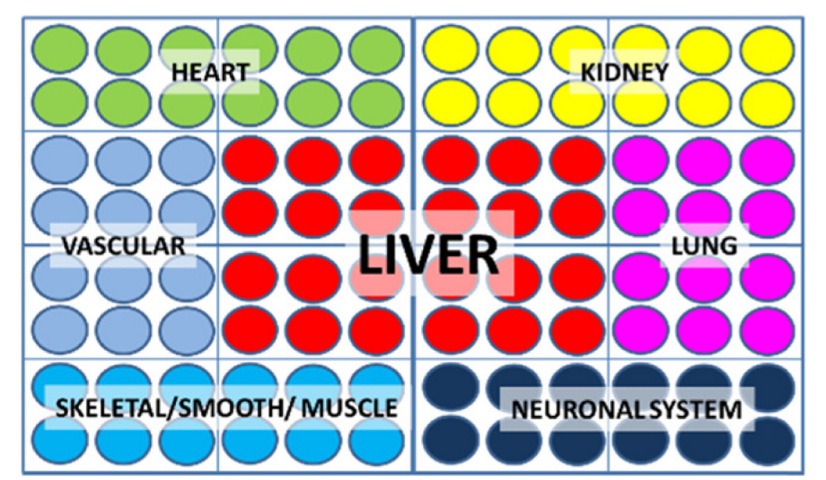

Fig. 7. Next generation IdMOC. This new IdMOC design has a single chamber with 48 wells or 96 wells (as shown), thereby allowing the co-culture of a relatively large number of cell types. An example is shown here with 24 wells of hepatocytes at the center of the plate surrounded by 12 wells for each of the key nonhepatic organs. This configuration allows the culturing of multiple cell types per organ. Each plate thereby models a single animal or human with the selected key organs. This new IdMOC configuration is thereby an in vitro system modeling the whole organism (Each of the organs is represented by a different color).

tiple organs is shown in Fig. 7.

\section{CONCLUSION AND FUTURE DIRECTIONS}

For accurate assessment of adverse drug effects, the clas- 
sical approach of total reliance on evaluation in laboratory animals is not adequate due to species differences. A new paradigm, HCP, is proposed here in which human-specific data are obtained using in vitro human-based experimental systems, and applied in combination with known human in vivo parameters (e.g. PBPK parameters) or with experimental results from relevant in vivo animal species, for a more accurate assessment of human in vivo effects.

Human hepatocytes represent an important experimental system for the definition of human-specific drug properties. Successful cryopreservation of human hepatocytes to retain viability and hepatic metabolism allow the cells to be used routinely for experimentation. Cryopreserved human hepatocytes are applied routinely in drug development for the evaluation of metabolic fate, P450 inhibition, P450 induction, in vitro hepatotoxicity, metabolism-based toxicity, and IdMOC ${ }^{\text {TM }}$ evaluation of hepatic metabolism on nonhepatic toxicity.

Drug-drug interactions using human hepatocytes is now routinely practiced in drug development and is required by government regulatory agencies for new drug approval. Hepatocytes are used for the definition of metabolic pathways, P450 inhibition and P450 induction. Recently, hepatocytes are used to define drug-drug interactions resulting from interaction of a drug with uptake and efflux transporters.

Unlike drug-drug interactions, in vitro toxicity evaluation is not yet regarded as a definitive approach to investigate drug safety in drug development. In vitro toxicity studies such as hepatocyte cytotoxicity screening are used for the prioritization of compound selection for further development. In some cases, where clinical toxicity is observed, in vitro systems are used for mechanistic evaluation to allow a better understanding of the physiological relevance of the findings and to develop approaches for the selection of safe alternatives. A major drawback of in vitro systems is the lack of the complex multiple-organ interaction. The $\mathrm{IdMOC}^{\mathrm{TM}}$ system and microfluidic approaches are steps towards this direction. The ultimate goal of accurate assessment of human drug toxicity will rely on the development of in vitro platforms with multiple organs, including the immune system, with each organ represented by multiple cell types and communication among organs achieved using human plasma or equivalent. Current advances in bioengineering and stem cell biology may allow this ultimate goal to be achieved. The development of multiple organ co-culture systems with hepatocytes and immune cells may also facilitate the identification of biomarkers for drug-induced liver injuries.

\section{REFERENCES}

1. Kola, I. and Landis, J. (2004) Can the pharmaceutical industry reduce attrition rates? Nat. Rev. Drug Discovery, 3, 711715.
2. Li, A.P. (2004) Accurate prediction of human drug toxicity: a major challenge in drug development. Chem. Biol. Interact., 150, 3-7.

3. Li, A.P. (2010) Evaluation of drug metabolism, drug-drug interactions, and in vitro hepatotoxicity with cryopreserved human hepatocytes. Methods Mol. Biol., 640, 281-294.

4. Baillie, T.A. and Rettie, A.E. (2011) Role of biotransformation in drug-induced toxicity: influence of intra- and interspecies differences in drug metabolism. Drug Metab. Pharmacokinet., 26, 15-29.

5. Easterbrook, J., Fackett, D. and Li, A.P. (2001) A comparison of aroclor 1254-induced and uninduced rat liver microsomes to human liver microsomes in phenytoin O-deethylation, coumarin 7-hydroxylation, tolbutamide 4-hydroxylation, Smephenytoin 4'-hydroxylation, chloroxazone 6-hydroxylation and testosterone 6beta-hydroxylation. Chem. Biol. Interact., 134, 243-249.

6. Lee, K., Vandenberghe, Y., Herin, M., Cavalier, R., Beck, D., Li, A., Verbeke, N., Lesne, M. and Roba, J. (1994) Comparative metabolism of SC-42867 and SC-51089, two PGE2 antagonists, in rat and human hepatocyte cultures. Xenobiotica, 24, 25-36.

7. Montastruc, F., Sommet, A., Bondon-Guitton, E., Durrieu, G., Bui, E., Bagheri, H., Lapeyre-Mestre, M., Schmitt, L. and Montastruc, J.L. (2012) The importance of drug-drug interactions as a cause of adverse drug reactions: a pharmacovigilance study of serotoninergic reuptake inhibitors in France. Eur. J. Clin. Pharmacol., 68, 767-775.

8. Takarabe, M., Shigemizu, D., Kotera, M., Goto, S. and Kanehisa, M. (2011) Network-based analysis and characterization of adverse drug-drug interactions. J. Chem. Inf. Model., 51, 2977-2985.

9. Assis, D.N. and Navarro, V.J. (2009) Human drug hepatotoxicity: a contemporary clinical perspective. Expert. Opin. Drug Metab. Toxicol., 5, 463-473.

10. Kaplowitz, N. (2013) Avoiding idiosyncratic DILI: two is better than one. Hepatology, 58, 15-17.

11. Stephens, C., Lucena, M.I. and Andrade, R.J. (2012) Genetic variations in drug-induced liver injury (DILI): resolving the puzzle. Front. Genet., 3, 253.

12. Hawkins, M.T. and Lewis, J.H. (2012) Latest advances in predicting DILI in human subjects: focus on biomarkers. Expert. Opin. Drug Metab. Toxicol., 8, 1521-1530.

13. Li, A.P. (2008) Human hepatocytes as an effective alternative experimental system for the evaluation of human drug properties: general concepts and assay procedures. Altex, 25, 33-42.

14. Li, A.P. (2007) Human hepatocytes: isolation, cryopreservation and applications in drug development. Chem. Biol. Interact., 168, 16-29.

15. Gómez-Lechón, M.J., Lahoz, A., Jiménez, N., Vicente Castell, J. and Donato, M.T. (2006) Cryopreservation of rat, dog and human hepatocytes: influence of preculture and cryoprotectants on recovery, cytochrome P450 activities and induction upon thawing. Xenobiotica, 36, 457-472.

16. Terry, C., Mitry, R.R., Lehec, S.C., Muiesan, P., Rela, M., Heaton, N.D., Hughes, R.D. and Dhawan, A. (2005) The effects of cryopreservation on human hepatocytes obtained from different sources of liver tissue. Cell Transplant., 14, 585-594. 
17. De Bruyn, T., Ye, Z.W., Peeters, A., Sahi, J., Baes, M., Augustijns, P.F. and Annaert, P.P. (2011) Determination of OATP-, NTCP- and OCT-mediated substrate uptake activities in individual and pooled batches of cryopreserved human hepatocytes. Eur. J. Pharm. Sci., 43, 297-307.

18. Kimoto, E., Yoshida, K., Balogh, L.M., Bi, Y.A., Maeda, K., El-Kattan, A., Sugiyama, Y. and Lai, Y. (2012) Characterization of organic anion transporting polypeptide (OATP) expression and its functional contribution to the uptake of substrates in human hepatocytes. Mol. Pharmaceutics, 9, 3535-3542.

19. Maeda, K., Kambara, M., Tian, Y., Hofmann, A.F. and Sugiyama, Y. (2006) Uptake of ursodeoxycholate and its conjugates by human hepatocytes: role of $\mathrm{Na}(+)$-taurocholate cotransporting polypeptide (NTCP), organic anion transporting polypeptide (OATP) 1B1 (OATP-C), and oatp1B3 (OATP8). Mol. Pharmaceutics, 3, 70-77.

20. Shitara, Y., Li, A.P., Kato, Y., Lu, C., Ito, K., Itoh, T. and Sugiyama, Y. (2003) Function of uptake transporters for taurocholate and estradiol 17beta-D-glucuronide in cryopreserved human hepatocytes. Drug Metab. Pharmacokinet., 18, 33-41.

21. Li, N., Zhang, Y., Hua, F. and Lai, Y. (2009) Absolute difference of hepatobiliary transporter multidrug resistance-associated protein (MRP2/Mrp2) in liver tissues and isolated hepatocytes from rat, dog, monkey, and human. Drug Metab. Dispos., 37, 66-73.

22. Li, M., Yuan, H., Li, N., Song, G., Zheng, Y., Baratta, M., Hua, F., Thurston, A., Wang, J. and Lai, Y. (2008) Identification of interspecies difference in efflux transporters of hepatocytes from dog, rat, monkey and human. Eur. J. Pharm. Sci., 35, 114-126.

23. Bi, Y.A., Kazolias, D. and Duignan, D.B. (2006) Use of cryopreserved human hepatocytes in sandwich culture to measure hepatobiliary transport. Drug Metab. Dispos., 34, 1658-1665.

24. Chen, Y., Liu, L., Monshouwer, M. and Fretland, A.J. (2011) Determination of time-dependent inactivation of CYP3A4 in cryopreserved human hepatocytes and assessment of human drug-drug interactions. Drug Metab. Dispos., 39, 2085-2092.

25. Xu, L., Chen, Y., Pan, Y., Skiles, G.L. and Shou, M. (2009) Prediction of human drug-drug interactions from time-dependent inactivation of CYP3A4 in primary hepatocytes using a population-based simulator. Drug Metab. Dispos., 37, 23302339.

26. Li, A.P. and Doshi, U. (2011) Higher throughput human hepatocyte assays for the evaluation of time-dependent inhibition of CYP3A4. Drug Metab. Lett., 5, 183-191.

27. McGinnity, D.F., Berry, A.J., Kenny, J.R., Grime, K. and Riley, R.J. (2006) Evaluation of time-dependent cytochrome P450 inhibition using cultured human hepatocytes. Drug Metab. Dispos., 34, 1291-1300.

28. Zhao, P., Kunze, K.L. and Lee, C.A. (2005) Evaluation of time-dependent inactivation of CYP3A in cryopreserved human hepatocytes. Drug Metab. Dispos., 33, 853-861.

29. Li, A.P. (2009) Metabolism comparative cytotoxicity assay (MCCA) and cytotoxic metabolic pathway identification assay (CMPIA) with cryopreserved human hepatocytes for the evaluation of metabolism-based cytotoxicity in vitro: proofof-concept study with aflatoxin B1. Chem. Biol. Interact., 179, 4-8.

30. Li, A.P., Uzgare, A. and LaForge, Y.S. (2012) Definition of metabolism-dependent xenobiotic toxicity with co-cultures of human hepatocytes and mouse $3 \mathrm{~T} 3$ fibroblasts in the novel integrated discrete multiple organ co-culture (IdMOC) experimental system: results with model toxicants aflatoxin B1, cyclophosphamide and tamoxifen. Chem. Biol. Interact., 199, 1-8.

31. Webb, D.J., Freestone, S., Allen, M.J. and Muirhead, G.J. (1999) Sildenafil citrate and blood-pressure-lowering drugs: results of drug interaction studies with an organic nitrate and a calcium antagonist. Am. J. Cardiol., 83, 21C-28C.

32. Li, A.P., Kaminski, D.L. and Rasmussen, A. (1995) Substrates of human hepatic cytochrome P450 3A4. Toxicology, 104, 1-8.

33. Zimmermann, M., Duruz, H., Guinand, O., Broccard, O., Levy, P., Lacatis, D. and Bloch, A. (1992) Torsades de Pointes after treatment with terfenadine and ketoconazole. Eur. Heart J., 13, 1002-1003.

34. Flockhart, D.A. (1996) Drug interactions, cardiac toxicity, and terfenadine: from bench to clinic? J. Clin. Psychopharmacol., 16, 101-103.

35. Ishizaki, T. (1996) Strategic proposals to avoid drug interactions during drug development: a lesson from a terfenadinerelated drug interaction. J. Toxicol. Sci., 21, 301-303.

36. Terrien, M.H., Rahm, F., Fellrath, J.M. and Spertini, F. (1999) Comparison of the effects of terfenadine with fexofenadine on nasal provocation tests with allergen. J. Allergy Clin. Immunol., 103, 1025-1030.

37. Borcherding, S.M., Baciewicz, A.M. and Self, T.H. (1992) Update on rifampin drug interactions. II. Arch. Intern. Med., 152, 711-716.

38. Holdiness, M.R. (1987) Rifampin drug interactions. Arch. Intern. Med., 147, 1856.

39. Baciewicz, A.M., Self, T.H. and Bekemeyer, W.B. (1987) Update on rifampin drug interactions. Arch. Intern. Med., 147, 565-568.

40. Baciewicz, A.M. and Self, T.H. (1984) Rifampin drug interactions. Arch. Intern. Med., 144, 1667-1671.

41. Offermann, G., Keller, F. and Molzahn, M. (1985) Low cyclosporin A blood levels and acute graft rejection in a renal transplant recipient during rifampin treatment. Am. J. Nephrol., 5, 385-387.

42. Müller, F. and Fromm, M.F. (2011) Transporter-mediated drug-drug interactions. Pharmacogenomics, 12, 1017-1037.

43. Zhang, L., Huang, S.M. and Lesko, L.J. (2011) Transportermediated drug-drug interactions. Clin. Pharmacol. Ther., 89, 481-484.

44. Lai, Y., Sampson, K.E. and Stevens, J.C. (2010) Evaluation of drug transporter interactions in drug discovery and development. Comb. Chem. High Throughput Screening, 13, 112-134.

45. Tsuji, A. (2002) Transporter-mediated Drug Interactions. Drug Metab. Pharmacokinet., 17, 253-274.

46. Maeda, K. and Sugiyama, Y. (2013) Transporter biology in drug approval: regulatory aspects. Mol. Aspects Med., 34, 711-718.

47. Zamek-Gliszczynski, M.J., Hoffmaster, K.A., Tweedie, D.J., Giacomini, K.M. and Hillgren, K.M. (2012) Highlights from the International Transporter Consortium second workshop. Clin. Pharmacol. Ther., 92, 553-556.

48. Zhang, L., Zhang, Y.D., Strong, J.M., Reynolds, K.S. and 
Huang, S.M. (2008) A regulatory viewpoint on transporterbased drug interactions. Xenobiotica, 38, 709-724.

49. Lee, J.I., Zhang, L., Men, A.Y., Kenna, L.A. and Huang, S.M. (2010) CYP-mediated therapeutic protein-drug interactions: clinical findings, proposed mechanisms and regulatory implications. Clin. Pharmacokinet., 49, 295-310.

50. Zhang, L., Zhang, Y. and Huang, S.M. (2009) Scientific and regulatory perspectives on metabolizing enzyme-transporter interplay and its role in drug interactions: challenges in predicting drug interactions. Mol. Pharmaceutics, 6, 1766-1774.

51. Müller, H.J. and Gundert-Remy, U. (1994) The regulatory view on drug-drug interactions. Int. J. Clin. Pharmacol. Ther., 32, 269-273.

52. Darnell, M., Ulvestad, M., Ellis, E., Weidolf, L. and Andersson, T.B. (2012) In vitro evaluation of major in vivo drug metabolic pathways using primary human hepatocytes and HepaRG cells in suspension and a dynamic three-dimensional bioreactor system. J. Pharmacol. Exp. Ther., 343, 134-144.

53. Gómez-Lechón, M.J., Donato, M.T., Castell, J.V. and Jover, R. (2004) Human hepatocytes in primary culture: the choice to investigate drug metabolism in man. Curr. Drug Metab., 5, 443-462.

54. Hong, H., Su, H., Ma, L., Yao, M., Iyer, R.A., Humphreys, W.G. and Christopher, L.J. (2011) In vitro characterization of the metabolic pathways and cytochrome P450 inhibition and induction potential of BMS-690514, an ErbB/vascular endothelial growth factor receptor inhibitor. Drug Metab. Dispos., 39, 1658-1667.

55. Khojasteh, S.C., Prabhu, S., Kenny, J.R., Halladay, J.S. and Lu, A.Y. (2011) Chemical inhibitors of cytochrome P450 isoforms in human liver microsomes: a re-evaluation of P450 isoform selectivity. Eur. J. Drug Metab. Pharmacokinet., 36, $1-16$.

56. Parkinson, A., Kazmi, F., Buckley, D.B., Yerino, P., Ogilvie, B.W. and Paris, B.L. (2010) System-dependent outcomes during the evaluation of drug candidates as inhibitors of cytochrome P450 (CYP) and uridine diphosphate glucuronosyltransferase (UGT) enzymes: human hepatocytes versus liver microsomes versus recombinant enzymes. Drug Metab. Pharmacokinet., 25, 16-27.

57. Doshi, U. and Li, A.P. (2011) Luciferin IPA-based higher throughput human hepatocyte screening assays for CYP3A4 inhibition and induction. J. Biomol. Screening, 16, 903-909.

58. Li, A.P. (2009) Evaluation of luciferin-isopropyl acetal as a CYP3A4 substrate for human hepatocytes: effects of organic solvents, cytochrome P450 (P450) inhibitors, and P450 inducers. Drug Metab. Dispos., 37, 1598-1603.

59. Li, A.P., Maurel, P., Gomez-Lechon, M.J., Cheng, L.C. and Jurima-Romet, M. (1997) Preclinical evaluation of drug-drug interaction potential: present status of the application of primary human hepatocytes in the evaluation of cytochrome P450 induction. Chem. Biol. Interact., 107, 5-16.

60. Pelletier, R.D., Lai, W.G. and Wong, Y.N. (2013) Application of a substrate cocktail approach in the assessment of cytochrome P450 induction using cultured human hepatocytes. $J$. Biomol. Screening, 18, 199-210.

61. Feidt, D.M., Klein, K., Hofmann, U., Riedmaier, S., Knobeloch, D., Thasler, W.E., Weiss, T.S., Schwab, M. and Zanger, U.M. (2010) Profiling induction of cytochrome p450 enzyme activity by statins using a new liquid chromatography-tandem mass spectrometry cocktail assay in human hepatocytes. Drug Metab. Dispos., 38, 1589-1597.

62. Lahoz, A., Donato, M.T., Picazo, L., Castell, J.V. and GómezLechon, M.J. (2008) Assessment of cytochrome P450 induction in human hepatocytes using the cocktail strategy plus liquid chromatography tandem mass spectrometry. Drug Metab. Lett., 2, 205-209.

63. Gerin, B., Dell'Aiera, S., Richert, L., Smith, S. and Chanteux, H. (2013) Assessment of cytochrome P450 (1A2, 2B6, 2C9 and 3A4) induction in cryopreserved human hepatocytes cultured in 48 -well plates using the cocktail strategy. Xenobiotica, 43, 320-335.

64. Halladay, J.S., Wong, S., Khojasteh, S.C. and Grepper, S. (2012) An 'all-inclusive' 96-well cytochrome P450 induction method: measuring enzyme activity, mRNA levels, protein levels, and cytotoxicity from one well using cryopreserved human hepatocytes. J. Pharmacol. Toxicol. Methods, 66, 270-275.

65. Einolf, H.J., Chen, L., Fahmi, O.A., Gibson, C.R., Obach, R.S., Shebley, M., Silva, J., Sinz, M.W., Unadkat, J.D., Zhang, L. and Zhao, P. (2014). Evaluation of various static and dynamic modeling methods to predict clinical CYP3A induction using in vitro CYP3A4 mRNA induction data. Clin. Pharmacol. Ther., 95, 179-188.

66. Fahmi, O.A., Kish, M., Boldt, S. and Obach, R.S. (2010) Cytochrome P450 3A4 mRNA is a more reliable marker than CYP3A4 activity for detecting pregnane $\mathrm{X}$ receptor-activated induction of drug-metabolizing enzymes. Drug Metab. Dispos., 38, 1605-1611.

67. Rautio, J., Humphreys, J.E., Webster, L.O., Balakrishnan, A., Keogh, J.P., Kunta, J.R., Serabjit-Singh, C.J. and Polli, J.W. (2006) In vitro p-glycoprotein inhibition assays for assessment of clinical drug interaction potential of new drug candidates: a recommendation for probe substrates. Drug Metab. Dispos., 34, 786-792.

68. Eberl, S., Renner, B., Neubert, A., Reisig, M., Bachmakov, I., König, J., Dörje, F., Mürdter, T.E., Ackermann, A., Dormann, H., Gassmann, K.G., Hahn, E.G., Zierhut, S., Brune, K. and Fromm, M.F. (2007) Role of p-glycoprotein inhibition for drug interactions: evidence from in vitro and pharmacoepidemiological studies. Clin. Pharmacokinet., 46, 1039-1049.

69. Ye, Z.W., Camus, S., Augustijns, P. and Annaert, P. (2010) Interaction of eight HIV protease inhibitors with the canalicular efflux transporter ABCC2 (MRP2) in sandwich-cultured rat and human hepatocytes. Biopharm. Drug Dispos., 31, 178-188.

70. Keppler, D. (2005) Uptake and efflux transporters for conjugates in human hepatocytes. Methods Enzymol., 400, 531-542.

71. Matsunaga, N., Nunoya, K., Okada, M., Ogawa, M. and Tamai, I. (2013) Evaluation of hepatic disposition of paroxetine using sandwich-cultured rat and human hepatocytes. Drug Metab. Dispos., 41, 735-743.

72. Marion, T.L., Perry, C.H., St Claire, R.L., 3rd and Brouwer, K.L. (2012) Endogenous bile acid disposition in rat and human sandwich-cultured hepatocytes. Toxicol. Appl. Pharmacol., 261, 1-9.

73. Lee, J.K., Marion, T.L., Abe, K., Lim, C., Pollock, G.M. and Brouwer, K.L. (2010) Hepatobiliary disposition of troglitazone and metabolites in rat and human sandwich-cultured hepatocytes: use of Monte Carlo simulations to assess the 
impact of changes in biliary excretion on troglitazone sulfate accumulation. J. Pharmacol. Exp. Ther., 332, 26-34.

74. Wolf, K.K., Vora, S., Webster, L.O., Generaux, G.T., Polli, J.W. and Brouwer, K.L. (2010) Use of cassette dosing in sandwich-cultured rat and human hepatocytes to identify drugs that inhibit bile acid transport. Toxicol. In Vitro, 24, 297-309.

75. Li, N., Bi, Y.A., Duignan, D.B. and Lai, Y. (2009) Quantitative expression profile of hepatobiliary transporters in sandwich cultured rat and human hepatocytes. Mol. Pharmaceutics, 6, 1180-1189.

76. Reyner, E.L., Sevidal, S., West, M.A., Clouser-Roche, A., Freiwald, S., Fenner, K., Ullah, M., Lee, C.A. and Smith, B.J. (2013) In vitro characterization of axitinib interactions with human efflux and hepatic uptake transporters: implications for disposition and drug interactions. Drug Metab. Dispos., 41, 1575-1583.

77. Barton, H.A., Lai, Y., Goosen, T.C., Jones, H.M., El-Kattan, A.F., Gosset, J.R., Lin, J. and Varma, M.V. (2013) Modelbased approaches to predict drug-drug interactions associated with hepatic uptake transporters: preclinical, clinical and beyond. Expert. Opin. Drug Metab. Toxicol., 9, 459-472.

78. Takanohashi, T., Kubo, S., Arisaka, H., Shinkai, K. and Ubukata, K. (2012) Contribution of organic anion transporting polypeptide (OATP) 1B1 and OATP1B3 to hepatic uptake of nateglinide, and the prediction of drug-drug interactions via these transporters. J. Pharm. Pharmacol., 64, 199-206.

79. Fahrmayr, C., Fromm, M.F. and Konig, J. (2010) Hepatic OATP and OCT uptake transporters: their role for drug-drug interactions and pharmacogenetic aspects. Drug Metab. Rev., 42, 380-401.

80. Kindla, J., Fromm, M.F. and König, J. (2009) In vitro evidence for the role of OATP and OCT uptake transporters in drug-drug interactions. Expert Opin. Drug Metab. Toxicol., 5, 489-500.

81. Soars, M.G., Webborn, P.J. and Riley, R.J. (2009) Impact of hepatic uptake transporters on pharmacokinetics and drugdrug interactions: use of assays and models for decision making in the pharmaceutical industry. Mol. Pharmaceutics, 6, 1662-1677.

82. Regev, A. (2013) How to avoid being surprised by hepatotoxicity at the final stages of drug development and approval. Clin. Liver Dis., 17, 749-767.

83. Giordano, C.M. and Zervos, X.B. (2013) Clinical manifestations and treatment of drug-induced hepatotoxicity. Clin. Liver Dis., 17, 565-573.

84. Hussaini, S.H. and Farrington, E.A. (2014) Idiosyncratic druginduced liver injury: an update on the 2007 overview. Expert. Opin. Drug Saf., 13, 67-81.

85. Shi, Q., Yang, X. and Mendrick, D.L. (2013) Hopes and challenges in using miRNAs as translational biomarkers for druginduced liver injury. Biomarkers Med., 7, 307-315.

86. Schomaker, S., Warner, R., Bock, J., Johnson, K., Potter, D., Van Winkle, J. and Aubrecht, J. (2013) Assessment of emerging biomarkers of liver injury in human subjects. Toxicol. Sci., 132, 276-283.

87. Persson, M., Løye, A.F., Mow, T. and Hornberg, J.J. (2013) A high content screening assay to predict human drug-induced liver injury during drug discovery. J. Pharmacol. Toxicol. Methods, 68, 302-313.
88. Pedersen, J.M., Matsson, P., Bergström, C.A., Hoogstraate, J., Norén, A., LeCluyse, E.L. and Artursson, P. (2013) Early identification of clinically relevant drug interactions with the human bile salt export pump (BSEP/ABCB11). Toxicol. Sci., 136, 328-343.

89. Li, A.P. (2002) A review of the common properties of drugs with idiosyncratic hepatotoxicity and the "multiple determinant hypothesis" for the manifestation of idiosyncratic drug toxicity. Chem. Biol. Interact., 142, 7-23.

90. Amacher, D.E. (2012) The primary role of hepatic metabolism in idiosyncratic drug-induced liver injury. Expert. Opin. Drug Metab. Toxicol., 8, 335-347.

91. Ballet, F. (2010) Back to basics for idiosyncratic drug-induced liver injury: dose and metabolism make the poison. Gastroenterol. Clin. Biol., 34, 348-350.

92. Boelsterli, U.A. (2003) Idiosyncratic drug hepatotoxicity revisited: new insights from mechanistic toxicology. Toxicol. Mech. Methods, 13, 3-20.

93. Claesson, A. and Spjuth, O. (2013) On mechanisms of reactive metabolite formation from drugs. Mini Rev. Med. Chem., 13, 720-729.

94. Saab, L., Peluso, J., Muller, C.D. and Ubeaud-Sequier, G. (2013) Implication of hepatic transporters (MDR1 and MRP2) in inflammation-associated idiosyncratic drug-induced hepatotoxicity investigated by microvolume cytometry. Cytometry A, 83, 403-408.

95. Warner, D.J., Chen, H., Cantin, L.D., Kenna, J.G., Stahl, S., Walker, C.L. and Noeske, T. (2012) Mitigating the inhibition of human bile salt export pump by drugs: opportunities provided by physicochemical property modulation, in silico modeling, and structural modification. Drug Metab. Dispos., 40, 2332-2341.

96. Kubitz, R., Dröge, C., Stindt, J., Weissenberger, K. and Haussinger, D. (2012) The bile salt export pump (BSEP) in health and disease. Clin. Res. Hepatol. Gastroenterol., 36, 536-553.

97. Moeller, T.A., Shukla, S.J. and Xia, M. (2012) Assessment of compound hepatotoxicity using human plateable cryopreserved hepatocytes in a 1536-well-plate format. Assay Drug Dev. Technol., 10, 78-87.

98. Ning, B., Bai, M. and Shen, W. (2011) Reduced glutathione protects human hepatocytes from palmitate-mediated injury by suppressing endoplasmic reticulum stress response. Hepatogastroenterology, 58, 1670-1679.

99. O’Brien, P.J., Chan, K. and Silber, P.M. (2004) Human and animal hepatocytes in vitro with extrapolation in vivo. Chem. Biol. Interact., 150, 97-114.

100. Dvorák, Z., Kosina, P., Walterová, D., Simánek, V., Bachleda, P. and Ulrichová, J. (2003) Primary cultures of human hepatocytes as a tool in cytotoxicity studies: cell protection against model toxins by flavonolignans obtained from Silybum marianum. Toxicol. Lett., 137, 201-212.

101. Prabhu, S., Fackett, A., Lloyd, S., McClellan, H.A., Terrell, C.M., Silber, P.M. and Li, A.P. (2002) Identification of glutathione conjugates of troglitazone in human hepatocytes. Chem. Biol. Interact., 142, 83-97.

102. Lloyd, S., Hayden, M.J., Sakai, Y., Fackett, A., Silber, P.M., Hewitt, N.J. and Li, A.P. (2002) Differential in vitro hepatotoxicity of troglitazone and rosiglitazone among cryopre- 
served human hepatocytes from 37 donors. Chem. Biol. Interact., 142, 57-71.

103. Li, A.P., Lu, C., Brent, J.A., Pham, C., Fackett, A., Ruegg, C.E. and Silber, P.M. (1999) Cryopreserved human hepatocytes: characterization of drug-metabolizing enzyme activities and applications in higher throughput screening assays for hepatotoxicity, metabolic stability, and drug-drug interaction potential. Chem. Biol. Interact., 121, 17-35.

104. Abraham, V.C., Towne, D.L., Waring, J.F., Warrior, U. and Burns, D.J. (2008) Application of a high-content multiparameter cytotoxicity assay to prioritize compounds based on toxicity potential in humans. J. Biomol. Screening, 13, 527537.

105. O’Brien, P.J., Irwin, W., Diaz, D., Howard-Cofield, E., Krejsa, C.M., Slaughter, M.R., Gao, B., Kaludercic, N., Angeline, A., Bernardi, P., Brain, P. and Hougham, C. (2006) High concordance of drug-induced human hepatotoxicity with in vitro cytotoxicity measured in a novel cell-based model using high content screening. Arch. Toxicol., 80, 580604.

106. Monteith, D.K. and Theiss, J.C. (1996) Comparison of tacrine-induced cytotoxicity in primary cultures of rat, mouse, monkey, dog, rabbit, and human hepatocytes. Drug Chem. Toxicol., 19, 59-70.

107. Kienhuis, A.S., van de Poll, M.C., Dejong, C.H., Gottschalk, R., van Herwijnen, M., Boorsma, A., Kleinjans, J.C., Stierum, R.H. and van Delft, J.H. (2009) A toxicogenomicsbased parallelogram approach to evaluate the relevance of coumarin-induced responses in primary human hepatocytes in vitro for humans in vivo. Toxicol. In Vitro, 23, 1163-1169.

108. Kier, L.D., Neft, R., Tang, L., Suizu, R., Cook, T., Onsurez, K., Tiegler, K., Sakai, Y., Ortiz, M., Nolan, T., Sankar, U. and Li, A.P. (2004) Applications of microarrays with toxicologically relevant genes (tox genes) for the evaluation of chemical toxicants in Sprague Dawley rats in vivo and human hepatocytes in vitro. Mutat. Res., 549, 101-113.

109. Zhang, J.D., Berntenis, N., Roth, A. and Ebeling, M. (2014) Data mining reveals a network of early-response genes as a consensus signature of drug-induced in vitro and in vivo toxicity. Pharmacogenomics J., 14, 208-216.

110. Dybing, E. and Mitchell, J.R. (1977) The role of metabolic activation for drug-induced liver injuries. Acta Pharmacol. Toxicol. (Copenhagen), 41 Suppl 2, 263-272.

111. Mitchell, J.R., Nelson, S.D., Thorgeirsson, S.S., McMurtry, R.J. and Dybing, E. (1976) Metabolic activation: biochemical basis for many drug-induced liver injuries. Prog. Liver Dis., 5, 259-279.

112. Wood, A.W., Levin, W., Lu, A.Y., Yagi, H., Hernandez, O., Jerina, D.M. and Conney, A.H. (1976) Metabolism of benzo(a)pyrene and benzo (a)pyrene derivatives to mutagenic products by highly purified hepatic microsomal enzymes. J. Biol. Chem., 251, 4882-4890.

113. Guengerich, F.P., Johnson, W.W., Shimada, T., Ueng, Y.F., Yamazaki, H. and Langouët, S. (1998) Activation and detoxication of aflatoxin B1. Mutat. Res., 402, 121-128.

114. Zhao, L. and Pickering, G. (2011) Paracetamol metabolism and related genetic differences. Drug Metab. Rev., 43, 41-52.

115. Veronese, M.E. and McLean, S. (1991) Metabolism of parac- etamol and phenacetin in relation to debrisoquine oxidation phenotype. Eur. J. Clin. Pharmacol., 40, 547-552.

116. Chang, T.K., Yu, L., Maurel, P. and Waxman, D.J. (1997) Enhanced cyclophosphamide and ifosfamide activation in primary human hepatocyte cultures: response to cytochrome P-450 inducers and autoinduction by oxazaphosphorines. Cancer Res., 57, 1946-1954.

117. Alley, M.C., Powis, G., Appel, P.L., Kooistra, K.L. and Lieber, M.M. (1984) Activation and inactivation of cancer chemotherapeutic agents by rat hepatocytes cocultured with human tumor cell lines. Cancer Res., 44, 549-556.

118. Corcoran, J., Lange, A., Winter, M.J. and Tyler, C.R. (2012) Effects of pharmaceuticals on the expression of genes involved in detoxification in a carp primary hepatocyte model. Environ. Sci. Technol., 46, 6306-6314.

119. González, R., Cruz, A., Ferrín, G., López-Cillero, P., Briceño, J., Gómez, M.A., Rufián, S., Padillo, J., De la Mata, M., Marin, J.J. and Muntané, J. (2011) Cytoprotective properties of rifampicin are related to the regulation of detoxification system and bile acid transporter expression during hepatocellular injury induced by hydrophobic bile acids. J. Hepatobiliary Pancreat. Sci., 18, 740-750.

120. Richter, P.A., Li, A.P., Polzin, G. and Roy, S.K. (2010) Cytotoxicity of eight cigarette smoke condensates in three test systems: comparisons between assays and condensates. Regul. Toxicol. Pharmacol., 58, 428-436.

121. Li, A.P. (2009) The use of the Integrated Discrete Multiple Organ Co-culture (IdMOC) system for the evaluation of multiple organ toxicity. Altern. Lab. Anim., 37, 377-385.

122. Li, A.P. (2007) Human-based in vitro experimental systems for the evaluation of human drug safety. Curr. Drug Saf., 2, 193-199.

123. Li, A.P. (2008) In vitro evaluation of human xenobiotic toxicity: scientific concepts and the novel integrated discrete multiple cell co-culture (IdMOC) technology. Altex, 25, 4349.

124. Li, A.P., Bode, C. and Sakai, Y. (2004) A novel in vitro system, the integrated discrete multiple organ cell culture (IdMOC) system, for the evaluation of human drug toxicity: comparative cytotoxicity of tamoxifen towards normal human cells from five major organs and MCF-7 adenocarcinoma breast cancer cells. Chem. Biol. Interact., 150, 129136.

125. Daniels, J.S., Lai, Y., South, S., Chiang, P.C., Walker, D., Feng, B., Mireles, R., Whiteley, L.O., McKenzie, J.W., Stevens, J., Mourey, R., Anderson, D. and Davis li, J.W. (2013) Inhibition of Hepatobiliary Transporters by A Novel Kinase Inhibitor Contributes to Hepatotoxicity in Beagle Dogs. Drug Metab. Lett., 7, 15-22.

126. Amacher, D.E. (2010) The discovery and development of proteomic safety biomarkers for the detection of druginduced liver toxicity. Toxicol. Appl. Pharmacol., 245, 134142.

127. Beger, R.D., Sun, J. and Schnackenberg, L.K. (2010) Metabolomics approaches for discovering biomarkers of druginduced hepatotoxicity and nephrotoxicity. Toxicol Appl Pharmacol 243, 154-166. 